\title{
Literatura e confiança: apontamentos sobre parâmetros de análise
}

\author{
[Literature and Trust: Notes on Analytical Tools] \\ http://dx.doi.ors/10.11606/1982-88372546209
}

Dionei Mathias $^{1}$

\begin{abstract}
Trust has a prominent role in the consolidation of self, of world apprehension and of human interactions. When literary texts represent interactions between subject and world, trust underlies motivations, actions and the transformations of meaning that emerge from such interactions. Parting from this perspective, this article aims to discuss the concept of trust in three spheres: individual, sociocultural and existential. To illustrate the argumentation, the article draws on three plays by Goethe: Torquato Tasso, Egmont and Iphigenia in Tauris. The introduction briefly outlines the place of trust in the discourse of Modernity. In the sections that follow, we seek to discuss each of the spheres and their representation in literary texts. The article concludes that trust as an analytical tool transcends national literary discourse, functioning as an instrument to identify new layers of meaning.
\end{abstract}

Keywords: Trust; Goethe; Torquato Tasso; Egmont; Iphigenia in Tauris.

Resumo: Confiança tem um lugar de destaque na consolidação do si, na apropriação de mundo e nas interações humanas. Quando textos literários representam interações entre sujeito e mundo, a confiança fundamenta motivações, ações e as transformações do sentido que emergem dessa interação. Nesse horizonte, este artigo deseja discutir o conceito de confiança em três esferas: individual, sociocultural e existencial. Para ilustrar a argumentação, o artigo recorre a três obras de Goethe: Torquato Tasso, Egmont e Ifigênia em Táurida. A introdução adumbra o lugar da confiança no discurso da Modernidade; nas seções que seguem busca-se refletir sobre cada uma das esferas e o modo como ela são representadas no texto literário. $\mathrm{O}$ artigo conclui que a confiança como parâmetro de análise transcende os discursos literários nacionais, funcionando como instrumento para identificar novas camadas de sentido.

Palavras-chave: Confiança; Goethe; Torquato Tasso; Egmont; Ifigênia em Táurida.

\section{Introdução}

O percurso da Modernidade talvez represente um projeto de investimento em confiança, buscando manter e estender o escopo desse recurso-chave para a concretização existencial. Com a fragilização das narrativas teológicas ao final da Idade Média, que

\footnotetext{
${ }^{1}$ Universidade Federal de Santa Maria, Departamento de Letras Estrangeiras Modernas, Avenida Roraima, 1000, Santa Maria, RS, 97105-900, Brasil. E-mail: dioneimathias@ gmail.com. ORCID: 0000-0001-84151460
}

(cc) BY-NC 
funcionavam como dispositivo para assegurar a estabilidade da confiança, tem início um movimento sociocultural que transfere paulatinamente o enfeixamento afetivo direcionado à instância divina em direção a seus sucedâneos modernos, isto é, à racionalidade, ao progresso, à emancipação. Com essa mudança na ordem dos discursos, também ocorre um deslocamento no depositário da confiança. Se antes ela se dirigia e provinha da instância divina, com a Modernidade ela passa a ter seu centro não mais num ser metafísico, mas no próprio indivíduo. Nessa esteira, Descartes ('Cogito, ergo sum'), mais tarde também Kant, a modo de exemplo, passam a enfeixar o raio da confiança intelectual nos potenciais individuais.

A definição clássica do Iluminismo parece representar o ápice desse deslocamento no investimento da confiança: "A menoridade é a incapacidade de fazer uso de seu entendimento sem a direção de outro indivíduo. O homem é o próprio culpado dessa menoridade se a causa dela não se encontra na falta de entendimento, mas na falta de decisão e coragem de servir-se de si mesmo sem a direção de outrem" (KANT 1985: 100). No lugar da providência divina que gere o percurso individual, o horizonte intelectual do final do século XVIII se encontra suscetível a enxergar no indivíduo o lugar onde a confiança é administrada. Assim, a responsabilidade pelo conhecimento não pode mais ser delegada, interpelando o indivíduo a direcionar sua confiança nas próprias faculdades mentais como caminho para obtenção do conhecimento. O percurso da confiança, nesse contexto, é duplo, pois o indivíduo é conclamado a confiar em si e, num segundo momento, no conhecimento racionalmente produzido. Na gênese do conceito de individualidade, portanto, a confiança tem um papel de destaque, pois é justamente o modo como ela é afetivamente gerida que permite uma transformação na constituição das narrativas do si.

Com a fragilização da confiança nas narrativas totalizantes ou nos grandes metarrelatos (LYOTARD 2009), talvez seja possível identificar um terceiro momentochave na forma de conceber o lugar da confiança. No bojo da barbárie nazista, a crença na racionalidade, no progresso e na emancipação perde seu lugar de destaque para abrir espaço a um novo conjunto de questionamentos. A confiança deixa de ser enfeixada em direção à totalização ou a sistemas filosóficos fechados para dar lugar ao princípio da desconstrução e da abertura. No lugar do sentido estável, semanticamente descritível, passa a imperar um sentido atravessado por instabilidade, ambivalência e constante disseminação. Esse movimento exige uma nova forma de administrar a confiança - não 
mais pautada pela instância divina, nem pelos sucedâneos modernos - para gerir o princípio da confiança no marco da dúvida. O paradoxo da confiança na dúvida parece representar um caminho para escapar da cegueira ideológica, mas também do fechamento do sentido, como forma de imposição narrativa.

Esses três estágios da história das ideias sugerem que a administração da confiança tem um lugar de destaque na produção de conhecimento e nas concepções do si, impactando de forma indireta no modo como as narrativas que pautam as visões de mundo são construídas. Se a confiança forma a base para a transformação das formatações discursivas - toda transformação pressupõe a confiança num novo modelo - ela também reverbera no modo como a literatura administra sua dinâmica de sentidos. Isso vale para a visão de mundo adotada na realidade diegética, pautando ações e posições de personagens ficcionais, mas também vale para a organização estética, revelando estratégias de administração de sentidos que consolidam ou desautomatizam práticas estabelecidas.

Para explorar essa ideia, o artigo discute o conceito de confiança a partir de três esferas: na esfera individual, na esfera cultural e no que diz respeito à condição humana, tentando identificar como as interações se concretizam com base nas diferentes modalidades de administração da confiança. Para ilustrar essas dinâmicas, recorre-se a três peças de Goethe: Torquato Tasso, Egmont, e Ifigênia em Táurida. Metodologicamente, o artigo não reconstrói o contexto discursivo de Goethe, buscando indícios em seus escritos para reforçar a leitura que se oferece. O caminho é inverso. Parte-se do conceito de confiança para identificar potenciais de sentido na obra do autor, privilegiando, desse modo, a dinâmica textual, em detrimento da voz autoral.

A obra de Goethe parece singularmente interessante para esse questionamento, por um lado, por se tratar de uma voz eminente na transição do Iluminismo para o período romântico, por outro lado, a confiança parece representar uma espécie de fio condutor, encontrando seu ápice no Fausto. Ao mesmo tempo, Goethe pavimenta o caminho para pensar literatura para além de seus muros nacionais, buscando compreender como outras formatações culturais pensam o si e suas relações com o mundo. Ao final de seu estudo sobre o papel da ciência em Goethe, Moura (2019: 344) conclui:

A intenção foi a de apresentar a possibilidade de se resgatar uma visão prazerosa da natureza, na qual o domínio seja suplantado pela empatia e que nos possibilite olhar para o vivente com mais vagar, procurando não a subtração de elementos cada vez mais essenciais para o estilo de vida que se escolheu levar, mas sim apresentando a alternativa, 
a possibilidade de novas escolhas, não tão práticas, mas que resgatam o humano em cada um de nós. Se é de utopia que se faz o futuro, Goethe estará inscrito nele.

Talvez seja possível pensar esse "olhar para o vivente" também a partir das dinâmicas de confiança, resgatando o humano com base nesse aspecto de “interdependência” e "correlação" (MourA 2019: 344). Trata-se de um olhar que, em seu vagar, está menos atento aos resultados pragmáticos ou utilitaristas e mais interessado em formas de pensar dinâmicas da convivência.

\section{Confiança na esfera individual}

A confiança representa o ponto de partida para interações sociais, mas também é a base de qualquer percurso identitário. O indivíduo precisa confiar em si e em suas habilidades para participar das diferentes dinâmicas sociais que o circundam e ele precisa confiar em seus interlocutores para dar início à construção de narrativas compartilhadas. Confiança, portanto, representa uma espécie de habilidade que vai definir de forma substancial o modo como cada sujeito se posiciona e circula no espaço social. Em grande medida, esse recurso afetivo tem sua fundamentação na primeira fase da existência. Em seu estudo paradigmático, Erikson fala de uma confiança primordial:

Para o pré-requisito mais fundamental da vitalidade mental, já indiquei um senso de confiança básica, que é uma atitude pervasiva em relação a si mesmo e ao mundo derivada das experiências do primeiro ano de vida. Por "confiança", quero dizer uma confiabilidade essencial dos outros, bem como um senso fundamental da própria confiabilidade (ERIKSON 1994: 96)².

Durante o processo de socialização na fase inicial da existência, portanto, o indivíduo aprende algo que precede a aquisição linguística. Talvez seja possível falar de uma semiótica afetiva ou de uma gramática dos afetos que estabelece o modo como esse sujeito pode enfeixar seus recursos emocionais para a obtenção daquilo que considera relevante para seu projeto identitário. Antes da língua como instrumento de acesso à realidade, parece haver uma retórica dos afetos que pavimenta o percurso existencial do sujeito. Em analogia às habilidades linguísticas, que definem em consonância com os recursos individuais como o sujeito se articula, obtém voz e participa (ou não) da

\footnotetext{
2 "For the most fundamental prerequisite of mental vitality, I have already nominated a sense of basic trust, which is a pervasive attitude toward oneself and the world derived from the experiences of the first year of life. By "trust" I mean an essential trustfulness of others as well as a fundamental sense of one's own trustworthiness" (ERIKSON 1994: 96).
} 
produção discursiva que prescrevem as regras do jogo, as habilidades afetivas parecem condicionar o modo como cada ator social se porta diante dos obstáculos do mundo.

Nessa esteira, o grau de confiança instilado na fase inicial se traduz numa atitude pessoal que transpira a exigência de atenção, a imposição da própria voz e a definição das modalidades de interação. O contrário também vem a lume, se a confiança primordial não tiver a fundamentação sólida necessária para a afirmação do si e de suas narrativas pessoais. Por baixo da crosta superficial da língua e de suas retóricas, há um núcleo afetivo cujo cerne se forma a partir da confiança primordial. Dessa perspectiva, a língua reflete uma dinâmica tectônica que remete a uma outra lógica que, em grande parte, permanece encoberta sob a crosta retórica e seus movimentos discursivos.

Thomas Fuchs (2015) retoma a ideia da confiança primordial e a estende para discutir confiança e familiaridade, buscando identificar como a dinâmica de apropriação de mundo, característica da primeira fase, se repete como estratégia ao longo da existência:

Em primeiro lugar, a pequena criança humana, na condição de "nascimento fisiologicamente prematuro", não tem à sua disposição as suas próprias capacidades físicas desde o início; seu corpo e esquema de ação estão desenvolvidos apenas rudimentarmente. Somente em experiências recorrentes de movimento espontâneo e uma resposta percebida do ambiente a criança gradualmente se acostuma com seu corpo e aprende a "habitá-lo", isto é, também de controlá-lo cada vez mais. Ao mesmo tempo, porém, se desenvolve a apropriação corporal do mundo, familiarizando-se [Vertrautwerden] com as formas, cores, sons e cheiros das coisas e aprendendo a lidar agindo com elas. Na medida em que a criança aprende a agir fisicamente com destreza, ela também aprende o uso e a adequação específica das coisas de seu entorno. Elas passam a estar literalmente "à mão"[zuhanden] para ela, ou seja, são incorporadas ao seu próprio corpo e esquema de ação, ao serem manejadas habilmente, (FUCHS 2015: 107)3.

Nessa descrição detalhada, o autor recupera o modo como bebês começam a construir uma casa no mundo. Ele usa a metáfora da casa para remeter à ideia da familiaridade que vai se instalando paulatinamente, na medida que a criança vai se apropriando de habilidades que lhe permitam controlar seu entorno. Na proporção que esse controle vai crescendo, aumenta a familiaridade com o espaço da ação e se estende

\footnotetext{
3 “Zunächst stehen dem kleinen Menschenkind als „physiologischer Frühgeburt" seine eigenen leiblichen Fähigkeiten nicht von vorneherein zur Verfügung; sein Körper- und Aktionsschema ist nur rudimentär entwickelt. Erst in wiederkehrenden Erfahrungen von spontaner Bewegung und wahrgenommener Antwort der Umgebung gewöhnt sich der Säugling nach und nach an seinen Körper und lernt ihn gleichsam zu „bewohnen“, d. h. auch zunehmend zu beherrschen. Im gleichen Zug entwickelt sich aber auch die leibliche Aneignung der Welt, das Vertrautwerden mit den Formen, Farben, Klängen und Gerüchen der Dinge, das Erlernen des handelnden Umgangs mit ihnen. In dem Maß wie das Kind leiblich geschickt zu agieren lernt, erlernt es auch den Gebrauch und die spezifische Eignung der Dinge seiner Umwelt. Sie werden ihm buchstäblich „zuhanden“, das heißt, in der geschickten Handhabung in das eigene Körper- und Aktionsschema eingegliedert" (FuCHS 2015: 107).
} 
o escopo da confiança. O que, num primeiro momento, vale para as habilidades físicas se estende para as dinâmicas afetivas, cognitivas e sociais. Como na primeira infância, o indivíduo vai tateando e experimentando a fim de identificar seus limites e verificar até que ponto o entorno permite a aproximação do si. Conforme os objetos e os atores sociais que circundam o sujeito passam a ser previsíveis e, com isso, passíveis de um determinado grau de controle, o indivíduo obtém maior confiança, aproximando-se e interagindo com o mundo, sem esperar comportamentos insidiosos que coloquem primeiramente seu corpo, posteriormente sua narrativa do si, em risco. As experiências iniciais estabelecem, de certa forma, as vigas da construção subjetiva, definindo as modalidades individuais de habitação. Com base nesse recurso, o indivíduo, em sua idade adulta, também se apropria do mundo, aproximando-se do outro ou recuando, de acordo com o grau de confiança. Antes da retórica mediada pelo signo linguístico, instale-se uma retórica afetiva que estabelece como cada sujeito vai transitar no espaço social.

O Torquato Tasso de Goethe parece particularmente apropriado para discutir a questão da confiança no nível individual, por apresentar um "psicograma diferenciado do artista moderno" (HINDERER 1997: 234). No desenvolvimento do enredo, o protagonista da peça precisa aprender a transitar entre diferentes códigos e comportamentos sociais. Uma parte desse aprendizado remete à identificação de seu lugar no mundo, o que implica uma problematização das diferentes formas de conceber a narrativa do si, diferenciando entre um modo mais contemplativo que caracteriza Tasso e um modo mais ativo que fundamenta o comportamento de Antônio. A partir de seu papel social de artista escritor, Tasso passa a transitar na corte, sendo acolhido pelo duque Afonso II e sua irmã Leonor, não somente na função de mecenas, mas também como uma espécie de figuras paternas. São eles que ensejam uma maior interação entre Tasso e Antônio, confrontando duas formas muito diferentes de ser no mundo (méritos artísticos contra méritos práticos). Nesse sentido, a peça apresenta dois movimentos-chave na instauração da confiança: por um lado, a interação do protagonista com a nobreza e seus códigos de conduta, por outro lado, a interação com Antônio e a alteridade de sua narrativa identitária. Na primeira, há uma diferença hierárquica, na segunda uma diferença de atitude diante do mundo. Nas duas situações, o protagonista tateia, a fim de verificar como pode se instalar nessa realidade, estabelecendo ou não malhas de confiança. 
MATHIAS, D. - Literatura e confiança

O primeiro eixo de confiança é foco de problematização na medida em que Tasso se instala na corte e começa a experimentar papeis sociais. Num primeiro momento, o duque contribui para que Tasso confie em si, no entorno e em seu talento:

Eu faço o que posso para incutir Ao seu ânimo firmeza e confiança.

Quantas vezes, em presença de muitos,

Lhe dou claros sinais do meu favor?

Se tem queixas, eu mando averiguar:

Como fiz quando há pouco suspeitou

Ter o quarto arrombado; quando nada

Se prova, acalmo-o com o meu conselho;

E como tudo se testa, o meu teste

De paciência é Tasso - ele merece,

$\mathrm{E}$ vós de bom grado me ajudareis.

(GOETHE 1999: 38).

O comportamento de Tasso, ao longo da peça, reiteradamente testa os limites da confiança, verificando ininterruptamente até que ponto consegue prever (e controlar) as ações que impactam sobre sua imagem. O duque, por sua vez, parece entender que o protagonista age no sentido de identificar espaços habitáveis, interagindo com outros atores sociais sempre com a finalidade de estabelecer até onde alcança sua confiança. Nessa esteira, o duque lhe concede a coroa de louros para reconhecer seus méritos, incitando os outros membros que circulam nesse espaço, incluindo Antônio, a investir na estabilização do recurso de confiança no horizonte de apropriação de realidade do protagonista.

Ao contrário de Antônio, cujo comportamento revela uma confiança primordial sólida e inquebrantável, Tasso hesita e duvida até mesmo na área de seu domínio:

Não sou digno de sentir a frescura Que só a fronte de heróis deve envolver.

Levai-me a coroa, oh deuses, dissipai-ma

Entre nuvens, para cada vez mais alto

Ela pairar distante, e a minha vida

Ser uma eterna marcha em sua busca!

(GOETHE 1999: 45) ${ }^{5}$.

\footnotetext{
4 "Ich tue, was ich kann, um Sicherheit/Und Zutraun seinem Busen einzuprägen./Ich geb ihm oft in Gegenwart von vielen/ Entschiedne Zeichen meiner Gunst. Beklagt/ Er sich bei mir, so laß ich's untersuchen,/ Wie ich es tat, als er sein Zimmer neulich/ Erbrochen glaubte. Läßt sich nichts entdecken,/ So zeig ich ihm gelassen, wie ich`s sehe;/ Und da man alles üben muß, so üb ich,/ Weil er`s verdient, an Tasso die Geduld:/ Und ihr, ich weiß es, steht mir willig bei. (GOETHE 1955c: 382).

5 "Ich bin nicht wert, die Kühlung zu empfinden,/ Die nur um die Heldenstirnen wehen soll./ O hebt ihn auf, ihr Götter, und verklärt/ Ihn zwischen Wolken, daß er hoch und höher/ Und unerreichbar schwebe! Daß mein Leben/ Nach dem Ziel ein ewig Wandeln sei!" (GOETHE 1955c: 386).
} 
MATHIAS, D. - Literatura e confiança

A despeito da confiança depositada nele por parte do duque, reconhecendo seus méritos intelectuais, Tasso não se sente "em casa" no papel social que seu entorno lhe atribui. A narrativa cuja tessitura se inicia com a coroa de louros permanece inabitável para o protagonista, o que, em outras palavras, significa que ele não confia nos próprios potenciais, a ponto de aceitar essa narrativa e utilizá-la como instrumento de autoencenação. Assim, a atitude de Tasso revela não uma confiança primordial, como no caso de Antônio, mas muito mais uma desconfiança primordial que o impede de encontrar estabilidade nos sentidos que busca desbravar em suas incursões sociais. Dessa perspectiva, ele entende que só pode legitimamente habitar esse espaço da confiança instaurado pela coroa de louros quem é herói, ou seja, aqueles que obtiveram reconhecimento de seus pares no mundo pragmático da medição de forças práticas. Embora Tasso busque um bom relacionamento com Antônio, ele pressente que seu interlocutor representa algo que ele não pode ser, habitando um espaço da confiança que não é o seu, o que produz uma atmosfera em que a desconfiança não retrocede.

Ao final da passagem, Tasso indica preferir entender a coroa (o reconhecimento, por extensão, a confiança) como eterna busca. $\mathrm{O}$ que, num primeiro momento, poderia ser compreendido com assomo de modéstia ou um esforço de constante transformação, preferindo o devir ao ser, talvez possa ser lido como estratégia para administrar a ausência da confiança primordial que o caracteriza. Nesse sentido, a superfície retórica apresenta uma narrativa que busca encobrir um hiato muito mais profundo, que o impede de transpor a ruptura causada pela inabilidade de confiar. É essa ruptura primordial que embarga interruptamente a construção de um espaço habitável em que possa estabelecer familiaridade e confiança.

Possivelmente esse anseio por um espaço da confiança primordial também seja o motivo que o impele a buscar por narrativas condenadas ao fracasso. Num diálogo com Leonor, Tasso revela sua insatisfação com a desconfiança do duque em relação a suas habilidades políticas, sugerindo ter conhecimentos que possam auxiliar no processo de tomada de decisão em questões práticas:

Ah, Leonor, que confiança é essa?

Alguma vez ele falou comigo

A sério sobre a sua política?

Se num ou noutro caso com a irmã

Conferenciava, e eu estava presente,

Aos outros consultava, não a mim. 
O que ouvia era: António está a chegar!

Escrevam a António! Perguntem a António!

(GOETHE 1999: 120) ${ }^{6}$.

A passagem reforça seu antagonismo em relação a Antônio, alimentando um sentimento de hostilidade para com seu opositor que, na lógica diegética, não está legitimado, já que seu suposto antagonista se esforça em manter relações cordiais com o protagonista. Num primeiro momento, a passagem ilustra a rivalidade que atravessa a peça, revelando um protagonista marcado por ciúmes, mas também por uma insegurança ininterrupta. Com a finalidade de debelar essa insegurança, o movimento de Tasso sugere um anseio de obter reconhecimento no âmbito do mundo pragmático, em que Antônio se sobressai. Na superfície retórica, surge um discurso do reconhecimento melindrado; na retórica afetiva se revela alguém que se embrenha em algo que não domina, a fim de obter um espaço de confiança.

Essa cegueira, que encobre uma busca desesperada por um espaço estável de confiança primordial, também se dirige a sua confidente Leonor. Quase no final da peça, Tasso crê que a princesa o ame, esquecendo o abismo social e as convenções dos códigos sociais, ao abraçá-la num voto cego de confiança. Com terror, ele constata que ela se afasta, após essa infração social inesperada. Também nesse episódio, seu anseio por confiança o impele a investir em narrativas que estão fora do seu alcance. Em ambas as situações, ele aposta nessas narrativas como promessas de obtenção do espaço primordial da confiança. Como no exemplo do exercício pragmático da política, o amor por Leonor talvez só mascare um hiato fundamental que o impede de se assentar. Essa inabilidade marca a diferença irredutível em relação a Antônio, como reflete a fala final de Tasso:

Oh, nobre António! Aí estás tu, tão firme,

E eu sou como a vaga na tempestade.

Mas pensa bem, e não te orgulhes tanto

Da tua força. A grande natureza

Que fez nascer a rocha, também deu

Às vagas a sua instabilidade.

(GOETHE 1999: 160)

\footnotetext{
6 "O Leonore, welch Vertraun ist das?/ Hat er von seinem Staate je ein Wort,/ Ein ernstes Wort mit mir gesprochen? Kam/ Ein eigner Fall, worüber er sogar/ In meiner Gegenwart mit seiner Schwester,/ Mit andern sich beriet, mit fragt' er nie./ Da hieß es immer nur: Antonio kommt!/ Man muß Antonio schreiben! Fragt Antonio!" (GOETHE 1955c: 436).

7 "O edler Mann! Du stehest fest und still,/ Ich scheine nur die sturmbewegte Welle./ Allein bedenk - und überhebe nicht/ Dich deiner Kraft! - die mächtige Natur,/ Die diese Felsen gründete, hat auch/ Der Welle die Beweglichkeit gegeben" (GOETHE 1955c: 465).
}

Pandaemonium, São Paulo, v. 25, n. 46, mai.-ago. 2022, p. 209-232 
Nessa leitura, as metáforas da "rocha" e da "vaga" como imagens de firmeza e instabilidade remetem a um recurso afetivo adquirido no processo de socialização de cada indivíduo, cujo teor é habilidade de confiar e se fincar no mundo, afirmando o si, a despeito dos questionamentos dirigidos à casa que o respectivo sujeito constrói. Ao contrário de Antônio, Tasso não encontra essa casa, repetindo a busca sem jamais encontrar estabilidade. Com isso, Tasso parece ter mais afinidade com o jovem Werther, enquanto Antônio tem mais proximidade com o Fausto, sedutor da jovem Margarida.

\section{Confiança na esfera sociocultural}

A dinâmica de instauração de confiança que se instala na esfera individual também emerge, devidamente transformada, na esfera social. Num nível mais amplo e complexo, os recursos e conhecimentos adquiridos na primeira fase da socialização são traduzidos para dinâmicas socioculturais, a partir das quais o indivíduo busca estabelecer espaços habitáveis. Aqui, o processo de socialização, de certo modo, recupera o conhecimento adquirido na incorporação de habilidades físicas, utilizando-o para a obtenção de confiança no plano das interações socioculturais, com sua diversidade de narrativas e práticas simbólicas. Nessa busca pela estabilização da confiança, o indivíduo tenta obter alguma forma de controle e previsibilidade sobre os resultados das interações sociais, mas também sobre sua concretização existencial.

Normas, valores, ética, até certo ponto, estabelecem narrativas de comportamento que servem como dispositivos para estabilizar o controle e assim obter um ambiente de confiança. Para Sasaki e Marsh, "a confiabilidade pode ser o resultado de uma ética estabelecida, com normas e valores sociais compartilhados. Valores e normas podem ser baseados em uma ética que é compartilhada antes do relacionamento, mas também podem se desenvolver conforme o relacionamento prossegue" (SASAKI; MARSH 2012: 14) ${ }^{8}$. No processo de negociação de identidades e da realidade que pauta o trânsito no mundo, indivíduos definem e reformulam o conjunto narrativo que orienta as modalidades da interação social. Tateando e experimentando, portanto, atores sociais identificam como cada sujeito deve se portar e o que pode esperar do seu contexto, a fim de concretizar seus

\footnotetext{
8 "Trustworthiness may be the result of an established ethic, with shared social norms and values. Values and norms may be based on an ethic that is shared prior to the relationship, but may also develop as the relationship proceeds" (SASAKI; MARSH 2012: 14).
} 
MATHIAS, D. - Literatura e confiança

planos no respectivo espaço social. Assim, normas, valores, ética estabelecem coordenadas iniciais, dentro das quais cada um define os parâmetros para a instauração de seu espaço de habitação, isto é, um espaço em que pode minimamente confiar e obter a sensação de controle.

O grau de estabilidade dessa confiança depende, em grande medida, de um conjunto de experiências a nível da interação individual, mas se estende igualmente para experiências representativas em diferentes agrupamentos como classe, raça, gênero, nação. Com base nessas experiências, emergem narrativas que servem como um primeiro crivo de apropriação de realidade e, portanto, de aproximação ao outro:

A confiança pode ser vista como um dispositivo [default], no sentido de que, com base na experiência passada, assumimos a confiabilidade a menos que encontremos novas evidências que a contradigam. Adaptamos as diretrizes anteriores de comportamento com base em novas evidências. [...] Assim, a ancoragem e a adaptação também podem ser uma heurística útil e justificada, tendo em vista a incerteza. No entanto, essas heurísticas podem gerar erros.

A relevância dessas heurísticas para a confiança é clara, porque elas afetam, ou permitem, a expectativa e atribuição de confiabilidade. De acordo com as heurísticas, seria possível desenvolver expectativas, explicar expectativas frustradas e atribuir confiabilidade de acordo com o que está "disponível" na mente, estereótipos, normas existentes ou experiência recente (SASAKI; MARSH 2012: 17) ${ }^{9}$.

Nesse cenário, confiança não é algo definitivo ou inquebrantável. A confiança primordial propicia uma atitude de abertura e acolhimento, contudo, a cada nova interação ela precisa ser confirmada, o que produz uma constante reavaliação do grau de confiança que pode ser depositada em agrupamentos sociais, narrativas culturais ou formas de conceber a realidade. Enquanto atores sociais se encontram disponíveis para a avaliação do grau de confiança, o diálogo ainda é possível, pois pressupõe uma atitude que ainda se encontra suscetível a acolher o outro, apostando em sua lhaneza.

Como fruto de avaliação, confiança também é passível de equívoco e de apostas desacertadas. No âmbito macrossocial, isso se explicita, por exemplo, quando instituições ou agentes públicos não cumprem as expectativas das quais são depositários. A confiança fragilizada fragmenta a coesão social, trazendo o risco da irrupção do caos. Os equívocos

\footnotetext{
9 "Trust can be seen as a default, in the sense that on the basis of past experience we assume trustworthiness unless we find new evidence that contradicts it. We adapt past guidelines for behaviour on the basis of new evidence. [...] Thus anchoring and adaptation may also be a useful and justified heuristic, in view of uncertainty. Nevertheless, these heuristics can yield errors.

The relevance of these heuristics to trust is clear, because they affect, or enable, expectation and attribution of trustworthiness. According to the heuristics, one would develop expectations, explain broken expectations, and attribute trustworthiness according to what is 'available' in the mind, stereotypes, existing norms or recent experience" (SASAKI; MARSH 2012: 17).
} 
também se revelam em forma de estereótipos ou de preconceitos. Assim, a confiança é depositada na narrativa que fundamenta essa visão de mundo, sem que o indivíduo se dê ao trabalho de verificar sua veracidade, optando por bloquear a negociação de outras formas de idear o espaço da vida. No lugar de alimentar a expectativa de lhaneza, antecipa-se um comportamento insidioso que destoa das normas do grupo.

Com o fechamento da disponibilidade para confiar no outro, não emerge somente o isolamento. Quando o fechamento ocorre a nível de grupo, ele não raramente representa o início de práticas de exclusão, discriminação e violência. Essa violência inicia com pequenas hostilidades, até se transformar num aparato de perseguição daqueles que não parecem dignos de confiança dos detentores de poder. Conforme cresce o grau de confiança na visão de mundo do próprio grupo, parece também crescer a disponibilidade do grupo de apostar na defesa de visão de mundo que legitima sua própria identidade. Aqui, confiança já não representa abertura para o diálogo e para a exploração de novos espaços da vida compartilhada, mas sim um risco crescente de cegueira que impele o indivíduo à violência em nome da narrativa de grupo.

Sasaki e Marsh descrevem essas duas atitudes como estruturas mentais básicas que definem as modalidades de percepção e, com isso, de apropriação de realidade:

A seleção e operação das heurísticas de decisão dependem de estruturas mentais. As pessoas operam com base em estruturas mentais, ou estados mentais, que moldam suas percepções e orientam seus atos, no uso de heurísticas de decisão. Relevantes para a confiança são duas estruturas mentais básicas: uma é orientada para 'proteger os seus recursos' e a outra para a 'solidariedade'. Na primeira, a atitude básica é de desconfiança, de medo da perda, e as ações do outro são escrutinadas como possíveis evidências de falta de confiabilidade, e a pessoa está pronta para retaliar ou tomar medidas preventivas. $\mathrm{Na}$ segunda, a atitude básica é de confiança, e se tende a ver as ações do outro como cooperativas (SASAKI; MARSH 2012: 18) ${ }^{10}$.

Nas duas situações, o indivíduo recebe, por meio das narrativas socioculturais, espaços habitáveis, para retomar a metáfora de Thomas Fuchs. Em ambos os casos, agrupamentos sociais apostam na respectiva narrativa, confiando nos potenciais que determinada narrativa oferece para que possa concretizar a existência de forma satisfatória ao lado daqueles que lhe são importantes. O que diferencia essas duas

\footnotetext{
10 "The selection and operation of decision heuristics depend on mental frames. People operate on the basis of mental frames, or states of mind, that shape their perceptions and guide their acts, in the use of decision heuristics. Relevant to trust are two basic frames of mind: one is oriented towards 'guarding your resources', and the other towards 'solidarity'. In the first the basic attitude is one of distrust, of being afraid of loss, and actions of the other are scrutinised as possible evidence of lack of trustworthiness, and one is ready to retaliate or take preventive action. In the second the basic attitude is one of trust, and one tends to see the actions of the other as cooperative" (SASAKI; MARSH 2012: 18).
} 
habitações da confiança reside na atitude diante do outro: uma cria muros antecipando a insídia; a outra se abre, esperando lhaneza. São essas duas atitudes que definem como cada indivíduo ou agrupamento social vai explorar novos espaços de confiança e instaurar espaços compartilhados da vida.

Isso vale para encontros entre agrupamentos sociais ou instituições dentro de um mesmo espaço cultural, mas se estende igualmente para o encontro com outras formatações culturais que buscam o diálogo:

Os contatos entre pessoas ou entre grupos, cedo ou tarde, dão origem a desentendimentos mais ou menos abertos, dependendo das questões, das afinidades e das capacidades de comunicação das pessoas. A experiência atual mostra que o sucesso de um encontro (no sentido de interação, troca, contato) anda de mãos dadas com o estabelecimento de um clima de confiança e que, na melhor das hipóteses, encontros bem-sucedidos podem dar origem a laços genuínos e duradouros de amizade, cuja confiança caracteriza e condiciona a estabilidade (MARANDON 2003: 259-260) ${ }^{11}$.

Nessa esteira, o diálogo que se entende aberto e disponível para o encontro com a alteridade pressupõe o desejo de investir na confiança. Trata-se de uma atitude, contudo, em que a disponibilidade para a confiança se revela aberta para apostar em narrativas alheias e rever as próprias visões de mundo. Onde essa disponibilidade se encontra bloqueada em forma de convicção única e exclusivamente na própria narrativa de grupo, a probabilidade de que a confiança possa, de fato, medrar permanece limitada.

No universo ficcional de Goethe, o protagonista Egmont da peça homônima se insere num conjunto de personagens caracterizados por uma confiança inabalável no mundo. $\mathrm{O}$ texto se revela interessante para discutir a questão da confiança na esfera social, pois está ambientado no momento histórico do levante holandês contra a invasão espanhola. Trata-se, portanto, de um contexto de extrema turbulência e instabilidade social (SCHUTZ 1997: 154), onde a administração da confiança tem um papel fundamental. Egmont, o conde holandês, e Alba, o duque espanhol, representam, portanto, duas esferas culturais diferentes, com interesses e visões de mundo que se chocam. A peça tem um foco claramente político ao problematizar as turbulências entre as potências do continente europeu e encenar a fragilidade do Estado como macronarrativa de organização do espaço social, uma narrativa ainda em progresso na

\footnotetext{
11 "Les contacts entre personnes ou entre groupes donnent tôt ou tard lieu à des désaccords plus ou moins déclarés, selon les enjeux, les affinités et les capacités des personnes à communiquer. L'expérience courante montre que le succès d'une rencontre (au sens d'interaction, échange, contact) va de pair avec l'établissement d'un climat de confiance, et que dans les meilleurs des cas des rencontres réussies peuvent donner lieu à des liens amicaux authentiques et durables, dont la confiance caractérise et conditionne la stabilité" (MARANDON 2003: 259-260).
} 
MATHIAS, D. - Literatura e confiança

ambientação histórica da peça, mas também no momento de produção por parte de Goethe. Nesse choque de interesse, Egmont representa as demandas do grupo dominado, com seus anseios de autonomia, participação e obtenção de voz própria. Alba, por sua vez, representa o grupo dominante, com sua política imperialista cujo esforço de volta para obtenção, manutenção e extensão do poder, não hesitando em instalar mecanismos de silenciamento de vozes destoantes ou subversivas.

O primeiro ato introduz o embate, com base nas diferenças religiosas. Enquanto os holandeses se identificam crescentemente com a nova religião protestante, as forças espanholas tentam manter a estabilidade do credo católico. A primeira cena ilustra o clima de desconfiança e incerteza entre representantes do povo; na segunda, ocorre um diálogo entre a regente e seu assessor Maquiavel, em que discutem a melhor estratégia de governo. No contexto desse diálogo Maquiavel declara:

Terão sido palavras talvez menos hábeis e menos piedosas do que verdadeiras. Como se pode esperar que haja confiança e que ela perdure, se os holandeses verificam que o interesse recai mais sobre o que possuem do que sobre o seu bem-estar ou sobre a salvação das suas almas? Não será verdade que os novos bispos se têm preocupado mais em banquetear-se com abundantes prebendas do que em salvar almas? E não são quase todos estrangeiros? Por enquanto o governo das províncias está nas mãos de holandeses, mas não é facto que os espanhóis dão claramente a entender que tais lugares lhes despertam a mais irreprimível das cobiças? (GOETHE 1993a: 300) ${ }^{12}$.

A fala do assessor expressa de forma condensada os vetores que atravessam esse espaço social, identificando os diferentes interesses de estabilizar narrativas identitárias, a partir das quais atores sociais possam se encenar e organizar as interações em seus espaços da vida. Com muita clareza e senso pragmático, Maquiavel expõe à regente espanhola o comportamento de seus conterrâneos, cuja motivação se volta explicitamente para a exploração (imperialista), ignorando sistematicamente os anseios da população local. O assessor, contudo, não se restringe somente a revelar à regente as diferentes motivações e seus possíveis resultados, ele estende essa reflexão à dinâmica afetiva inerente à balança da confiança. Nessa esteira, Maquiavel compreende que a coesão social está diretamente atrelada à manutenção da confiança na narrativa macrossocial. Sem a confiança das classes subordinadas, ele antecipa o risco de ruptura e resistência. Seu nome é revelador. Como estrategista, ele reconhece que não há narrativa social que medre, sem

12 "Vielleicht hat er wahrer als klug und fromm gesprochen. Wie soll Zutrauen entstehen und bleiben, wenn der Niederländer sieht, daß es mehr um seine Besitztümer als um sein Wohl, um seiner Seele Heil zu tun ist? Haben die neuen Bischöfe mehr Seelen gerettet als fette Pfründen geschmaust, und sind es nicht meist Fremde? Noch werden alle Statthalterschaften mit Niederländern besetzt; lassen sich es die Spanier nicht zu deutlich merken, daß sie die größte, unwiderstehlichste Begierde nach diesen Stellen empfinden?" (GOETHE 1955a: 234). 
a instauração sólida de confiança. Isso vale para regimes democráticos, mas se estende igualmente para práticas totalitárias.

O segundo ato introduz o protagonista e o caracteriza como alguém que possui uma confiança primordial inabalável, nas palavras do secretário, "a despreocupação está de acordo com a vossa maneira de ser" (GOETHE, 1993a: 333) ${ }^{13}$. Olhando para o mundo dessa perspectiva, Egmont não consegue imaginar que as forças espanholas poderiam representar um risco: "Não, Orange, não é possível. Quem se poderia atrever a pôr-nos a mão em cima?” (GoETHE, 1993a: 339) ${ }^{14}$. Pautado por essa atitude, Egmont também é o único que não muda seus hábitos quando as forças de opressão espanhola se instalam nos Países Baixos, para dar início a uma política de perseguição a dissidentes (GOETHE, 1993a: 372). Com efeito, na conversa entre Alba e Egmont, o protagonista sugere, com a lhaneza que o caracteriza, o princípio da confiança mútua como base para a construção de um convívio pacífico (GoETHE, 1993a: 380). Egmont não procura a ruptura, nem o confronto explícito, embora identifique a política imperialista das forças invasoras. Com base na confiança, ele propõe um terceiro caminho em que os interesses de ambas as partes possam confluir, isto é, um exercício do pensamento democrático. Esse comportamento não é irrelevante para o contexto da peça, pois Egmont é um dos poucos atores políticos habilitados a oferecer resistência ao maquinário de silenciamento e à insídia sistematizada, representados por Alba.

Diante de Alba, Egmont pondera os perigos de confiar num homem só ou na minoria que o rodeia, também considera pior o rei (detentor do poder) que intimida e que não acolhe aqueles que questionam suas ações (GOETHE 1993a: 382-383). A lhaneza de Egmont é sua mais admirável virtude, mas também sua sentença de morte. Ele assume que seus interlocutores vão adotar os mesmos princípios de retidão para negociar as narrativas macrossociais e, assim, chegar a um consenso que permita o convívio pacífico. Aqui, como em Götz von Berlichingen, a confiança excessiva se revela como uma armadilha que encaminha o protagonista à destruição. A morte como desfecho de tragédia é uma exceção em Goethe. Aqui, ela parece funcionar como alerta. Egmont se sacrifica desnecessariamente, por conta de sua atitude confiante, num contexto onde sua presença (e resistência) são indispensáveis. Sua confiança desmesurada produz uma cegueira que

13 "Es ziemt Euch, nicht zu sorgen, aber wer Euch kennt und liebt -" (GOETHE 1955a: 253).

14 "Nein, Oranien, es ist nicht möglich. Wer sollte wagen. Hand an uns zu legen?" (GOETHE 1955a: 258). 
MATHIAS, D. - Literatura e confiança

não só encerra sua existência, como também solapa um projeto de pensamento democrático, representado por suas ações.

Já condenado à morte, Egmont recebe a visita de Fernando, filho de Alba. Tratase de uma personagem secundária, mas de suma importância para a dinâmica de confiança. Após ter esclarecido que não compactua com as intenções do pai, ele se torna emissário do legado de Egmont. Este o incumbe de cuidar de Clara e se torna depositário das esperanças do protagonista. Só, Egmont faz um acerto final:

Malvado homem! Não poderias imaginar o serviço que me prestavas ao enviar-me o teu filho! Graças a ele estou agora liberto das preocupações, do sofrimento, do temor, de todos os sentimentos que me podiam atormentar. É é com uma insistência doce que a natureza exige seu último tributo. Tudo passou. Está tudo decidido. E o que ainda a noite passada me não deixava dormir e me mantinha na incerteza é o que hoje me vem embalar os sentidos com uma certeza que nada pode destruir (GOETHE 1993a: 414) ${ }^{15}$.

A despeito da sentença de morte, a peça termina com uma afirmação da confiança. A certeza que Egmont obtém nos momentos finais parece estar atrelada à confiança nos potenciais democráticos. Em Fernando, ele possivelmente enxerga uma força de resistência que enfeixa sua energia vital em direção à construção de um espaço social que busca fortalecer narrativas interessadas no princípio da liberdade, da participação mais igualitária e do convívio mais fraterno. Esse legado de confiança não é transferido automaticamente, ele precisa ser conquistado e alimentado por cada nova geração.

\section{Confiança na esfera existencial}

A última esfera, à falta de um termo melhor, tem o atributo de existencial. Trata-se da confiança investida no futuro e no projeto civilizatório de humanidade. O termo "projeto civilizatório" é empregado com a devida desconfiança, ciente dos perigos inerentes às narrativas totalizantes e seus flertes com a barbárie, ciente de que foi a narrativa da civilização que legitimou por séculos a exploração sistemática dos continentes americano, africano e asiático, em favor do enriquecimento de algumas nações do continente europeu, ciente, por fim, do campo semântico atrelado ao lexema "civilizatório" (civitas, civil, civilizado, civilização, civilizatório remetendo etimologicamente ao espaço urbano,

\footnotetext{
15 "Feindseliger Mann! Du glaubtest nicht, mir diese Wohltat durch deinen Sohn zu erzeigen. Durch ihn bin ich der Sorgen los und der Schmerzen, der Furcht und jedes ängstlichen Gefühls. Sanft und dringend fordert die Natur ihren letzten Zoll. Es ist vorbei, es ist beschlossen! Und was die letzte Nacht mich ungewiß auf meinem Lager wachend hielt, das schläfert nun mit unbezwinglicher Gewißheit meine Sinnen ein" (GOETHE 1955a: 305).
} 
vide LIMA 2012) que revela sua tentativa de hierarquização das formas de ser no mundo, não só de forma positiva, mas também instaurando estratégias de deslegitimação em relação àqueles que não pertencem ao próprio grupo (o bárbaro, o selvagem, o descortês, o vilão). O termo definitivamente apresenta uma carga semântica historicamente problemática e ele não deixa de conter um movimento de categorização, posicionando indivíduos nas coordenadas intra e extramuros de pertencimento. Ao mesmo tempo, contudo, também condensa uma estratégia de convívio social que se pauta por um interesse em criar espaço onde a confiança possa medrar e assim atenuar as incertezas sobre incursões insidiosas. Esse anseio por um espaço de confiança como projeto de futuro não se restringe aos assim chamados civilizados, em sua acepção etimológica, ele pode se estender igualmente àqueles denominados de bárbaros, selvagens, vilões.

O projeto civilizatório - não único, mas múltiplo - como projeto de futuro faz uma oferta de confiança, a fim de dar continuidade àquilo que constitui a condição humana, esta não entendida como um atributo universal, mas sim atravessada pelas diferentes narrativas culturais que dão corpo à sua imaginação. Atrelada a essa imaginação de futuro, obviamente também se encontram os vetores teleológicos que definem as modalidades de obtenção de sentido. Nessa esteira, Stevenson e Haberman (1998), contrapõem, por exemplo, a oferta de sentido oriunda respectivamente do pensamento cristão e marxista, em sua discussão sobre as teorias da condição humana:

Implícitas nessas prescrições rivais se encontram diferentes visões de um futuro no qual a humanidade será redimida ou regenerada. A visão cristã é de pessoas restituídas ao estado que Deus deseja para elas, amando e obedecendo livremente ao seu Criador. A nova vida começa assim que o indivíduo aceita a salvação de Deus e se junta à comunidade cristã, mas o processo deve ser concluído além da morte, pois os indivíduos e as comunidades são para sempre imperfeitos nesta vida. A visão marxista é de um futuro neste mundo, de uma sociedade perfeita na qual as pessoas podem se tornar seres reais, não mais alienadas pelas condições econômicas, mas livremente ativas em cooperação umas com as outras. Esse é o objetivo da história, embora não deva ser esperado imediatamente após a revolução; um estágio de transição será necessário antes que a fase superior da sociedade comunista possa surgir (STEVENSON; HABERMAN 1998: 7) ${ }^{16}$.

\footnotetext{
16 "Implicit in these rival prescriptions are differing visions of a future in which humankind is redeemed or regenerated. The Christian vision is of people restored to the state that God intends for them, freely loving and obeying their Maker. The new life begins as soon as the individual accepts God's salvation and joins the Christian community, but the process must be completed beyond death, for individuals and communities are forever imperfect in this life. The Marxist vision is of a future in this world, of a perfect society in which people can become real selves, no longer alienated by economic conditions but freely active in cooperation with one another. Such is the goal of history, although it should not be expected immediately after the revolution; a transitional stage will be needed before the higher phase of communist society can come into being" (STEVENSON; HABERMAN 1998: 7).
} 
Cada uma dessas duas macronarrativas paradigmáticas oferece à sua comunidade de adeptos um conjunto de sentidos que prevê como imaginar o convívio social, como idear o futuro e, sobretudo, um projeto de humanidade que, de uma ou outra forma, investe sua energia cognitiva em pensar modalidades do pacto civilizatório. Para que essas narrativas causem impacto nas ações e interações concretas, é necessário que uma comunidade confie nos pressupostos que elas apresentam, formando uma comunidade que compartilhe uma visão de futuro similar, adequando atos e volições no sentido de corresponder às expectativas inerentes aos respectivos projetos.

Essas macronarrativas de futuro, com suas modalidades de imaginar o andamento do projeto de civilização, também fornecem um conjunto de instrumentos para obtenção de controle sobre a incerteza que caracteriza o futuro. Elas, portanto, formam uma base para a estabilização da confiança. Na definição de Piotr Sztompka, a incerteza tem um papel de destaque nesse contexto: "Agindo em condições incertas e incontroláveis, corremos riscos, jogamos, fazemos apostas sobre as incertas futuras ações livres de outros. Assim, chegamos à definição simples e mais geral de confiança: confiança é uma aposta sobre as ações contingentes futuras de outros" (SzTOMPKA 2003: 25) ${ }^{17}$. A necessidade de redução da incerteza está ligada a normas, valores ou outras narrativas culturais, discutidos na seção anterior, mas talvez seja possível estender esse entendimento para a esfera existencial, no sentido, de identificar na narrativa de futuro não só a base para a confiança em nível de grupo étnico ou comunidade cultural, mas sim numa narrativa da condição humana, como projeto de um futuro compartilhado.

A incerteza de todo futuro e o fato de que "cooperação é um empreendimento precário" (BARBALET 1996: 77) ${ }^{18}$ também impactam nas narrativas do projeto de civilização. O futuro do convívio da humanidade foi uma questão importante em diferentes momentos da História e o continua sendo mais que nunca, especialmente num momento onde a distribuição desigual de chances se transforma em prática sistematizada da exclusão, onde o espaço da vida está sistematicamente à mercê das veleidades do capital, onde as novas práticas de mediação da informação servem como instrumento para enfeixar ódios e invejas, em massa. As diferentes narrativas de futuro sobre a condição

17 "Acting in uncertain and uncontrollable conditions, we take risks, we gamble, we make bets about the future uncertain, free actions of others. Thus we have arrived at the simple, most general definition of trust: trust is a bet about the future contingent actions of others" (SZTOMPKA 2003: 25).

18 "Cooperation is a precarious enterprise" (BARBALET 1996: 77). 
humana oferecem caminhos para administrar a energia afetiva, em analogia ao que ocorre em nível interacional:

A confiança é baseada em algo diferente e menos certo ou sólido do que o conhecimento, ou seja, uma crença ou um sentimento. Isso se conecta com a ideia de que a confiança é sempre baseada em um certo tipo de expectativa; a confiança, então, é por sua natureza orientada para o futuro. A confiança não é simplesmente uma crença ou sentimento sobre outra pessoa, mas uma crença ou sentimento sobre o que essa pessoa provavelmente fará no futuro (BARBALET 2019: 14) ${ }^{19}$.

Também nesse nível da escala global, com seu projeto de futuro da condição humana articulado em maior ou menor grau de consciência, a confiança representa uma aposta. Essa aposta pode se voltar para o princípio do ódio e da hostilidade ou ela pode se dirigir ao princípio da solidariedade e do acolhimento. Por trás dessas duas formas de concretizar a ação, há narrativas de mundo que explicam ao indivíduo como deve organizar seus sentidos existenciais, como deve imaginar o futuro e, sobretudo, em que verdade deve confiar. O modo como essa confiança é enfeixada não impacta somente o nível da interação individual, tampouco se restringe somente aos interesses de uma comunidade nacional; as consequências do investimento de confiança, por vezes, definem como o projeto civilizatório vai se concretizar, definindo os parâmetros da esfera existencial.

A obra epistolar de Goethe revela o papel central da ideia de humanidade em seu pensamento e seus potenciais de recepção, como conclui Mazzari (2019: 247) ao escrever: "pois dessas cartas respira igualmente a profunda humanidade que Walter Benjamin invocou em sua luta contra o fascismo". De todas as peças de Goethe, talvez Ifigênia em Táurida seja a que mais se insere na discussão sobre a esfera existencial, no sentido de projeto de civilização e humanidade. Ambientada na Grécia antiga, a peça tem um lugar de destaque no projeto estético do Classicismo de Weimar, tendo um foco especial na discussão sobre o conceito de humanidade. A peça dirige sua atenção ao destino de Ifigênia. Exilada em Táurida, a protagonista precisa conquistar a confiança de Toas, rei de Táurida, e mais tarde, a confiança de Orestes, seu irmão. Essa confiança remete primeiramente a um nível pessoal da interação, onde os interlocutores testam até que ponto podem debelar a incerteza das ações dos outros no marco da confiança. Ao mesmo tempo, a peça encena a imaginação de um ideal de futuro, em que os diferentes partidos

19 "Trust is based on something other than, and less certain or solid than knowledge, namely a belief or a feeling. This connects with the idea that trust is always based on a certain type of expectation; trust, then, is by its nature future orientated. Trust is not simply a belief or feeling about another person but a belief or feeling about what that person is likely to do in the future" (BARBALET 2019: 14). 
MATHIAS, D. - Literatura e confiança

são interpelados a renunciar a visões etnocêntricas, com seus interesses de grupo, a fim de pensar um convívio pautado por outras configurações de sentido. A Ifigênia cabe expor essa narrativa do ideal de humanidade, em que a lei do mais forte retrocede a fim de dar voz a um pensamento de respeito pela vida do outro. Na leitura de Reed (1997: 197), "não mais a violência supera violência, não gregos a bárbaros, mas sim o humano [supera] o primitivo" ${ }^{20}$. Na base dessa narrativa, encontra-se a confiança como ponto de partida para a construção do futuro.

Em um diálogo com Arcas na cena inicial, Ifigênia já revela a visão de mundo e o conjunto de sentidos que motivam seus atos e que vão pautar o desfecho da peça. São as palavras de Arcas que a caracterizam:

Perdoo-te o orgulho nobre que te faz

De ti própria descrer, e só lamento

Que do prazer da vida ele te prive.

Nada fizeste desde que chegaste?

Quem alegrou a tristeza do rei?

Quem foi que, com suave persuasão,

Com o correr dos anos suspendeu

$\mathrm{O}$ antigo e cruel uso de aos estrangeiros

Sacrificar no altar de Diana,

$\mathrm{E}$ tantas vezes os prisioneiros fadados

A morte certa mandou de volta à pátria?

(GOETHE 1993b: 208-209) ${ }^{21}$.

Como Antônio ou Egmont, Ifigênia traz a lume uma confiança primordial inabalável, a despeito de suas palavras. A descrença de que fala Arcas remete à melancolia experimentada pela protagonista, ao constatar a limitação de seu escopo de ação. Em grande parte, seu desapontamento parece estar atrelado às limitações de sua agência, mas também a um anseio de voltar a sua terra natal. Dessa configuração, a confiança emerge em diferentes formas: Ifigênia não suprime o anseio pelo retorno, embora os seus, especificamente seu pai, tenham optado por seu sacrifício em nome dos interesses de estado; e Ifigênia não se curva ao papel subordinado previsto para o seu "destino", a despeito da violência patriarcal de seu pai. A despeito do evento traumático, a protagonista alimenta uma confiança inquebrantável no mundo.

\footnotetext{
20 "Nicht mehr Gewalt überwindet Gewalt, nicht Griechen Barbaren, sondern das Humane das Primitive“ (REED 1997: 197).

21 "Den edlen Stolz, daß du dir selbst nicht gnügest,/ Verzeih ich dir, so sehr ich dich bedaure;/ Er raubet den Genuß des Lebens dir./ Du hast hier nichts getan seit deiner Ankunft?/ Wer hat des Königs trüben Sinn erheitert?/ Wer hat den alten grausamen Gebrauch,/ Daß am Alter Dianens jeder Fremde/ Sein Leben blutend läßt, von Jahr zu Jahr/ Mit sanfter Überredung aufgehalten,/ Und die Gefangnen vom gewissen Tod/ Ins Vaterland so oft zurückgeschickt? " (GOETHE 1955b: 314).
} 
Essa confiança inabalável também é a base para seu projeto de humanização na corte de Toas. Como mulher, estrangeira e vítima de trauma, Ifigênia reúne um conjunto de fatores que, em princípio, a predispõem para o silêncio, ainda mais num espaço social onde a máquina da guerra dominada por homens define as regras do jogo. Apesar dessas condicionantes, ela identifica formas de ação e resistência ao princípio da barbárie. Com base numa imaginação de futuro que prevê outra forma do convívio humano, Ifigênia consegue, num processo paulatino, suspender a lei do mais forte e o princípio da violência e instaurar uma prática de respeito à vida alheia. Com isso, a protagonista não se opõe somente ao modelo estrangeiro de Toas, ela se opõe igualmente aos imperativos de sua própria socialização cultural, perfazendo um movimento de transcendência da cegueira étnica. Essa fala inicial revela como Ifigênia se contrapõe aos modelos herdados, a fim de tecer sua própria narrativa de futuro, com sua visão de projeto de civilização. A confiança que inspira é tamanha, que o próprio Toas não só suspende o sacrifício de estrangeiros, mas se sente inclinado a desposá-la, investindo confiança plena naquilo que Ifigênia representa, independentemente de sua origem.

Quando mais tarde encontra Orestes e Pílades e é confrontada com um plano de traição, Ifigênia hesita. O plano insidioso lhe promete o retorno e a proteção do irmão, mas inclui no mesmo movimento destruir os vínculos de confiança com Toas e, sobretudo, com sua própria narrativa de futuro. Ao contrário de seu irmão, Ifigênia não consegue se fechar para as vozes contrárias (GOETHE 1993b: 263). O que a protagonista parece identificar são duas formas diferentes de gerir a confiança e, com isso, a incerteza do futuro. Nessa perspectiva, o fechamento para dúvidas não só remete para uma forma de assegurar a determinação, ele também indica como confiança se transforma num instrumento, descartável, na medida em que já não tem mais utilidade concreta. Em oposição a essa visão de mundo utilitarista, Ifigênia adota um outro parâmetro de gestão dos sentidos, investindo na responsabilidade inerente à instauração de laços de confiança, independentemente dos resultados pragmáticos. Se no primeiro momento, ela ainda hesita, mais tarde a confiança na própria visão de mundo aumenta, a ponto de confessar a Toas o plano de seu irmão. Nesse diálogo, ela expõe de forma clara sua versão do convívio humano:

Apressamo-nos a aceitar uma lei

Que serve de arma às nossas paixões.

Outra lei a mim me fala, mais antiga,

E me faz resistir-te: aquela lei

Para a qual todo o forasteiro é sagrado. 
(GOETHE 1993b: 269) $)^{22}$.

O movimento empreendido pela protagonista se afasta dos impulsos e das visões voltadas para os interesses exclusivamente individuais, a fim de dirigir sua atenção ao outro e sua necessidade. No lugar do imperativo do si e sua vantagem na economia simbólica, ela adota um crivo que se esforça em enxergar o universo do outro. Esse movimento primeiramente revela uma confiança sólida na visão alternativa de futuro, afastando-se dos modelos herdados para pensar em outras configurações de gerir o convívio humano. Ao mesmo tempo, Ifigênia revela uma confiança firme nos potenciais de bondade, do perdão e da renovação. Com isso, sua narrativa de futuro não se pauta por uma lógica da vingança, da violência ou do confronto, mas sim de encontro com o outro.

Em sua fala final, Orestes constata: "Por tua ação volto a fruir da luz/ Plena do dia" (GOETHE 1993b: 280)23. Essa luz, que decorre das ações de Ifigênia, restaura a confiança no sentido existencial e inspira, ao mesmo tempo, a confiança numa narrativa que abandona "astúcia e força" como elemento motriz para imaginar o futuro. Nessa mesma esteira, Orestes convida Toas para o pacto de civilização, marcado por paz e confiança. As palavras finais de Ifigênia permanecem como convite para consolidar essa versão de futuro: "Dá-me/ A tua mão para selar uma amizade" (GOETHE 1993b: 281) ${ }^{24}$. Como em todas outras formatações da confiança, esta também precisa ser conquistada e reforçada a cada nova geração. É essa negociação interrupta que vai definir como a incerteza do futuro será debelada por meio de narrativas e suas malhas de sentido.

\section{Considerações finais}

Como parâmetro de pesquisa, a representação literária das dinâmicas inerentes ao princípio da confiança não se restringe à obra de Goethe e não se limita à literatura de expressão alemã. Como recurso primordial, a confiança está na base da condição humana. As diferentes formatações culturais vão traçar os percursos de obtenção, manutenção e extensão da confiança. As práticas literário-nacionais vão definir o que se torna foco de atenção e que malha simbólica é adotada a fim de problematizar suas dinâmicas. Isso também impacta nas periodizações: a literatura de cunho religioso no século XVI, por

\footnotetext{
22 "Wir fassen ein Gesetz begierig an,/ Das unsrer Leidenschaft zur Waffe dient./ Ein andres spricht zu mir, ein älteres,/ Mich dir zu widersetzen, das Gebot,/ Dem jeder Fremde heilig ist" (GoETHE, 1955b: 360).

23 "Neu/ Genieß ich nun durch dich das weite Licht/ Des Tages" (GOETHE, 1955b: 368).

24 "Und reiche mir/ Zum Pfand der alten Freundschaft deine Rechte" (GOETHE, 1955b: 370).
} 
MATHIAS, D. - Literatura e confiança

exemplo, problematiza a confiança a partir de interesses completamente diferentes daqueles adotados por uma prática literária que se volta para a gênese da nação no século XIX. A mesma diferença é identificável entre um discurso literário que ainda aposta na autonomia e na emancipação, como é o caso do século XVIII, e um discurso que já não consegue mais confiar nesses metarrelatos, como é o caso da segunda metade do século $\mathrm{XX}$. Com isso, o longo percurso da Modernidade apresenta diversas formas de pensar e administrar a confiança, mas em todas as etapas ela tem um papel fundamental na construção de um imaginário do si e do mundo.

\section{Referências bibliográficas}

BARBALET, Jack M. Social emotions: confidence, trust and loyalty. International Journal of Sociology and Social Policy, v. 16, n. 9/10, 75-96, 1996.

BARBALET, Jack. The Experience of Trust: Its Content and Basis. In: SASAKI, Masamichi (Org.). Trust in Contemporary Society. Leiden: Brill, 2019, 11-30.

ERIKSON, Erik H. Identity, Youth and Crisis. New York/London: W. W. Norton \& Company, 1994.

FUCHS, Thomas. Vertrautheit und Vertrauen als Grundlagen der Lebenswelt. In: BERMES, Christian; HAND, Annika (Org.). Lebenswelt und Lebensform. Hamburg: Felix Meiner Verlag, 2015, 101-117.

GoETHE, Johann Wolfgang. Egmont. Ein Trauerspiel in fünf Aufzügen. In: GoETHE, Johann Wolfgang. Gesammelte Werke in sieben Bänden. Zweiter Band: Dramen. Bernt von Heiseler (Org.). Gütersloh: Bertelsmann, 1955a, 223-307.

GOETHE, Johann Wolfgang. Iphigenie auf Tauris. Ein Schauspiel. In: GOETHE, Johann Wolfgang. Gesammelte Werke in sieben Bänden. Zweiter Band: Dramen. Bernt von Heiseler (Org.). Gütersloh: Bertelsmann, 1955b, 309-370.

GoETHE, Johann Wolfgang. Torquato Tasso. Ein Schauspiel. In: GoETHE, Johann Wolfgang. Gesammelte Werke in sieben Bänden. Zweiter Band: Dramen. Bernt von Heiseler (Org.). Gütersloh: Bertelsmann, 1955c, 371-466.

GoETHE, Johann Wolfgang. Egmont. Tragédia em cinco actos. Tradução: José M. Justo. In: GOETHE, Johann Wolfgang. Obras dramáticas. Lisboa: Círculo de Leitores, 1993a, 203281.

GoETHE, Johann Wolfgang. Ifigênia em Táurida. Um drama. Tradução: João Barrento. In: GOETHE, Johann Wolfgang. Obras dramáticas. Lisboa: Círculo de Leitores, 1993b, 283417.

GoETHE, Johann Wolfgang. Torquato Tasso. Tradução: João Barrento. Prefácio: Maria Filomena Molder. Lisboa: Relógio D’Água Editores, 1999.

HINDERER, Walter. Torquato Tasso. In: BUCK, Theo (Org.). Goethe Handbuch. Band 2. Dramen. Stuttgart/Weimar: Verlag J. B. Metzler, 1997, 229-257.

LIMA, Luís Filipe Silvério. Civil, civilidade, civilizar, civilização: usos, significados e tensões nos dicionários de língua portuguesa (1562-1831). Almanack, n. 3, 66-81, 2012.

LYOTARD, Jean François. A condição pós-moderna. Tradução: Ricardo Corrêa Barbosa. Rio de Janeiro: José Olympio, 2009. 
MATHIAS, D. - Literatura e confiança

KANT, Immanuel. Resposta à pergunta: Que é 'Esclarecimento' (Aufklärung). In: KANT, Immanuel. Textos seletos. Tradução: Raimundo Vier e Floriano de Souza Fernandes. Petrópolis: Vozes, 1985, 99-116.

MARANDON, Gérard. Au-delà de l'empathie, cultiver la confiance: clés pour la rencontre interculturelle. Revista CIDOB d'Afers Internacionals, n. 61-62, 2003, 259-282.

MAZZARI, Marcus Vinícius. "O humano que jamais nos abandona": A obra epistolar de Goethe. Estudos Avançados, v. 33, n. 96, 225-252, 2019.

MourA, Magali. A ciência de Goethe: Em busca da imagem do vivente. Estudos Avançados, v. 33, n. 96, 339-369, 2019.

REED, Terence James. Iphigenie auf Tauris. In: BUCK, Theo (Org.). Goethe Handbuch. Band 2. Dramen. Stuttgart/Weimar: Verlag J. B. Metzler, 1997, 195-228.

SASAKI, Masamichi; MARSH, Robert M. Introduction. In: SASAKI, Masamichi; MARSH, Robert M. (Org.). Trust. Comparative Perspectives. Leiden: Brill, 2012, 1-30.

SCHUTZ, Georg-Michael. Egmont. In: BuCK, Theo (Org.). Goethe Handbuch. Band 2. Dramen. Stuttgart/Weimar: Verlag J. B. Metzler, 1997, 154-172.

Stevenson, Leslie; Haberman, David L. Ten Theories of Human Nature. Oxford: Oxford University Press, 1998.

SzTompKA, Piotr. Trust. A Sociological Theory. Cambridge: Cambridge University Press, 2003.

Recebido em 6 de setembro de 2021 Aceito em 2 de outubro de 2021 